ресурсы с учетом всех влияющих на то специфичных характеристик автотранспортного средства.

$$
* * *
$$

1. Иорш В., Антоненко И. Внедрение информационной системы ТОиР: начало пути. [Электронный pecypc]. URL: http://www.cfin.ru/itm/kis/choose/mro.shtml (дата обращения: 10.11.2017).

2. Назарова О.Б.,Давлеткиреева Л.З.Интеграция автоматизированных информационных систем в сфере продаж холдинговой компании//Актуальные вопросы научной и научно-педагогической деятельности молодых учёных: сборник научных трудов всероссийской заочной научнопрактической конференции/под ред. Е.С. Ефремовой. Москва, 2015. -С. 86-96.

3. Назарова О.Б., Давлеткиреева Л.З., Малахова И.В. Аудит информационной инфраструктуры компании и разработка ИТ-стратегии: монография/О.Б. Назарова, Л.З. Давлеткиреева, И.В. Малахова. - Магнитогорск: Магнитогорский гос. ун-т, 2012. -223 с.

4. Назарова О.Б.,Новикова Т.Б.,Петеляк В.Е.К вопросу разработки диаграммы «архитектура системы ASD»//B сборнике: Современная наука: теоретический и практический взгляд Сборник статей Международной научно-практической конференции. Ответственный редактор: Сукиасян Асатур Альбертович. 2015. С. 75-77.

5. Положение о техническом обслуживании и ремонте подвижного состава автомобильного транспорта. - Утверждено Министерством автомобильного транспорта РСФСР 20 сентября 1984 года (последнее издание).

6. Руцков Е., Данилова Е. ПОдля автоматизации процессов управления ТОиР. [Электронный ресурс]. URL: https://www.iemag.ru/analitics/detail.php?ID=16122(дата обращения: 10.11.2017).

7. Саганенко А.А., Стебелев П.Н., Новикова Т.Б. Разработка моделей описания бизнес-процесса «Выполнение заявки на ремонт автомобиля» с использованием методологии ARIS // Современные научные исследования и инновации. 2016. № 11 [Электронный ресурс]. URL: http://web.snauka.ru/issues/2016/11/73122 (дата обращения: 10.11.2017).

\title{
Чернаткина E.M. \\ Аудит состояния автоматизированной информационной системы учета продаж производственного предприятия
}

Магнитогорский государственный технический университет им. Г. И. Носова

(Россия, Магнитогорск)

doi:10.18411/spc-12-11-2017-08

idsp: 000001:spc-12-11-2017-08

На производственном предприятии используется корпоративная информационная система (КИС), обеспечивающая полномасштабный учет в едином информационном пространстве всех операций компании по продажам, отгрузкам и оплатам.

Аудит состояния информационных систем предполагает инвентаризацию действующих ИТ-решений, степени их документированности, уровня обученности конечных пользователей и качества сопровождения.

В рамках обозначенных границ аудита проанализируем одну из конфигураций КИС 1С: УПП, а именно «Управление торговлей»

Основные критерии анализа:

1) состав конфигурации и перечень функций;

2) степень покрытия бизнес-процессов организации функциональностью системы;

3) степень документированности системы;

4) уровень обученности конечных пользователей.

\section{Состав конфигурации и перечень функций}

Конфигурация КИС 1С: УПП «Управление торговлей» позволяет автоматизировать задачи контроля и анализа торговых операций в комплексе со смежными задачами управленческого учета:

- планирование продаж и планирование закупок;

- управление отношениями с клиентами (CRM);

- управление поставками и запасами; 
- управление взаиморасчетами с контрагентами.

Тем самым обеспечивается эффективное управление торговым бизнесом современного предприятия. Конфигурация поддерживает следующие разновидности торговли: оптовую торговлю (продажу в кредит, продажу по предоплате, торговлю по заказам), розничную торговлю (продажи в торговом зале и удаленных неавтоматизированных точках), комиссионную торговлю (включая прием и передачу товаров на реализацию, а также субкомиссию).

Конфигурация имеет следующие функциональные возможности:

- построение различных схем формирования цен и скидок;

- контроль за соблюдением сотрудниками установленной ценовой политики;

- хранение информации о ценах конкурентов и поставщиков;

- сопоставление отпускных цен предприятия с ценами поставщиков и конкурентов;

- использование накопительных скидок по дисконтным картам.

Основными пользователями конфигурации являются: менеджеры по продажам и главный менеджер. Диаграмма вариантов использования представлена на рис. 1.

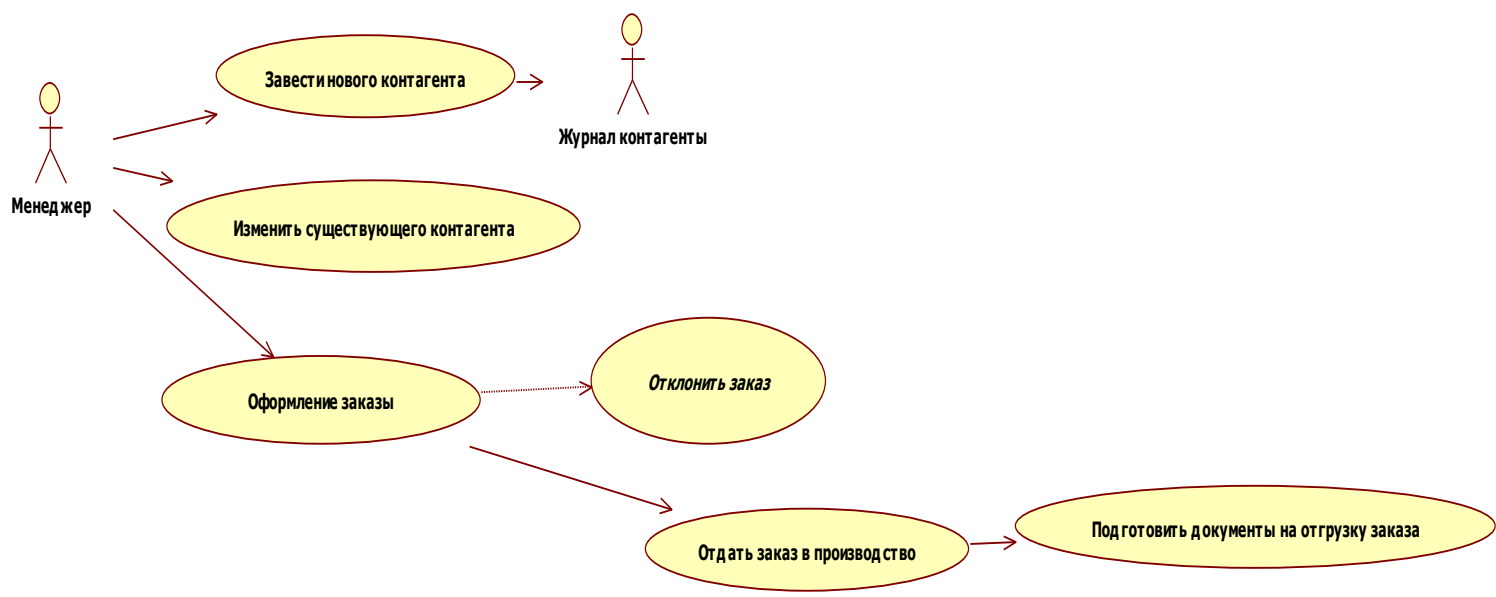

Рисунок 1 - Диаграмма вариантов использования

Конфигурация позволяет формировать различные виды отчетов на всех уровнях управления заказами.

\section{системы}

Степень покрытия бизнес-процессов компании функциональностью

Для того чтобы определить насколько существующая КИС покрывает бизнеспроцессы по управлению торговлей рассмотрим организацию деятельности отдела сбыта.

В начале месяца топ-менеджер отдела сбыта получает план продаж и список задач, составляет индивидуальные планы для каждого менеджера.

При работе с клиентами все заявки (включая потенциальные, когда клиент просто решил рассчитать стоимость предполагаемого заказа) оформляются в КИС и распечатываются. Один экземпляр счета передают клиенту, второй экземпляр остается у менеджера отдела сбыта.

Наличные денежные средства, полученные за заказ, сдаются в конце дня в бухгалтерию. В кассе при получении денежных средств оформляется приходный кассовый ордер. Квитанция к приходному кассовому ордеру, подтверждающая оплату, выдается на руки менеджеру, который осуществляет сдачу денежных средств.

На оформление заявки затрачивается от 10 до 20 минут. Перед оформление заявки менеджеры консультируют клиента и помогают рассчитать необходимый объем 
заказываемых материалов. На одну консультации тратится от 10 до 30 минут (все зависит от того, насколько клиент осведомлен о видах номенклатуры и его представления о предоставляемых услугах). В конце месяца формируются отчеты.

На основании описанных анализа деятельности отдела сбыта были построены функциональная IDEF0-модель «AS-IS» и модель событийно-управляемого процесса ARIS eEPC. Модели представлены на рис.2-3.

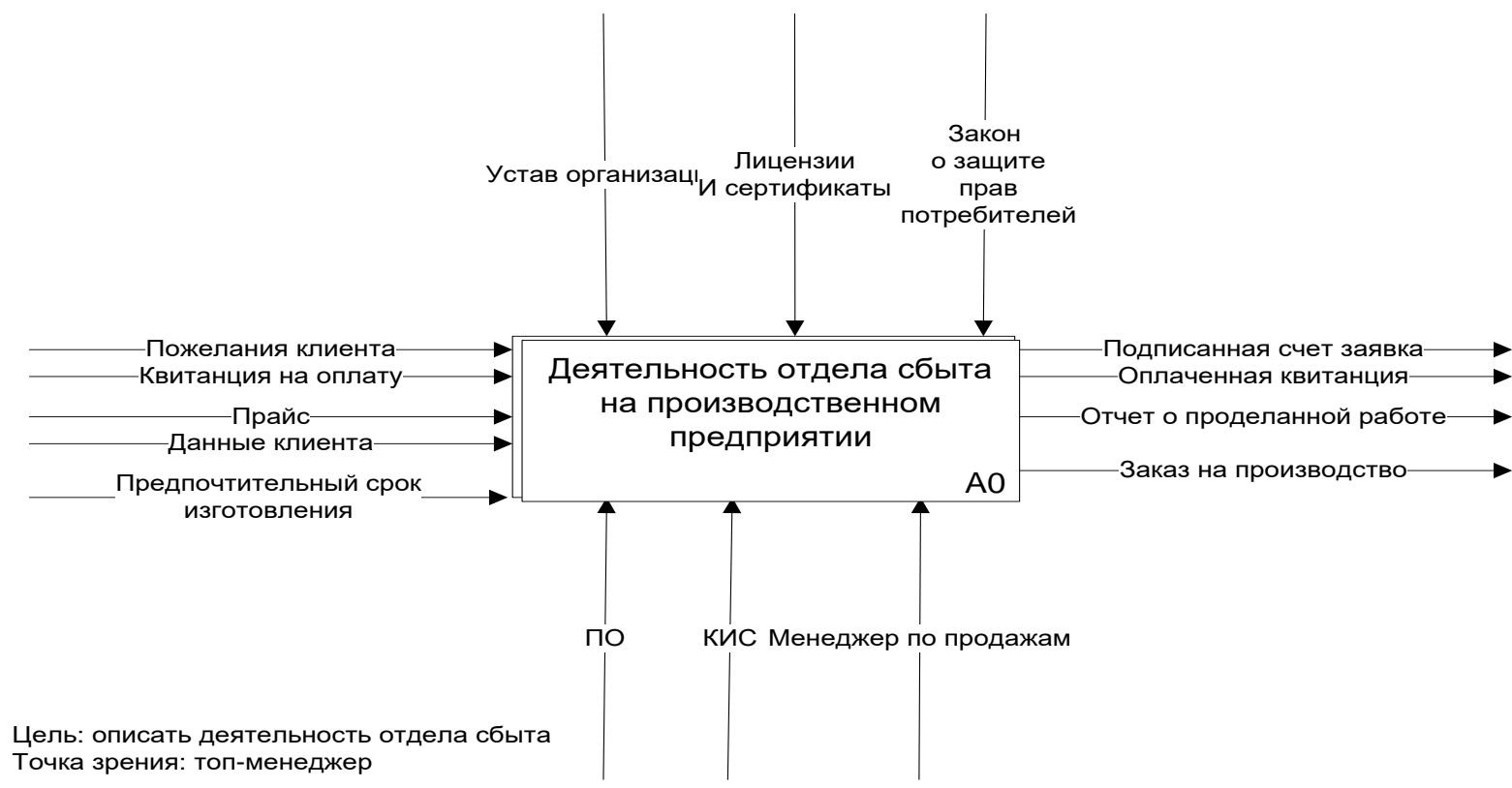

Рисунок 2 - Контекстная диаграмма функииональной IDEF0-модели «Организация деятельности отдела сбыта»

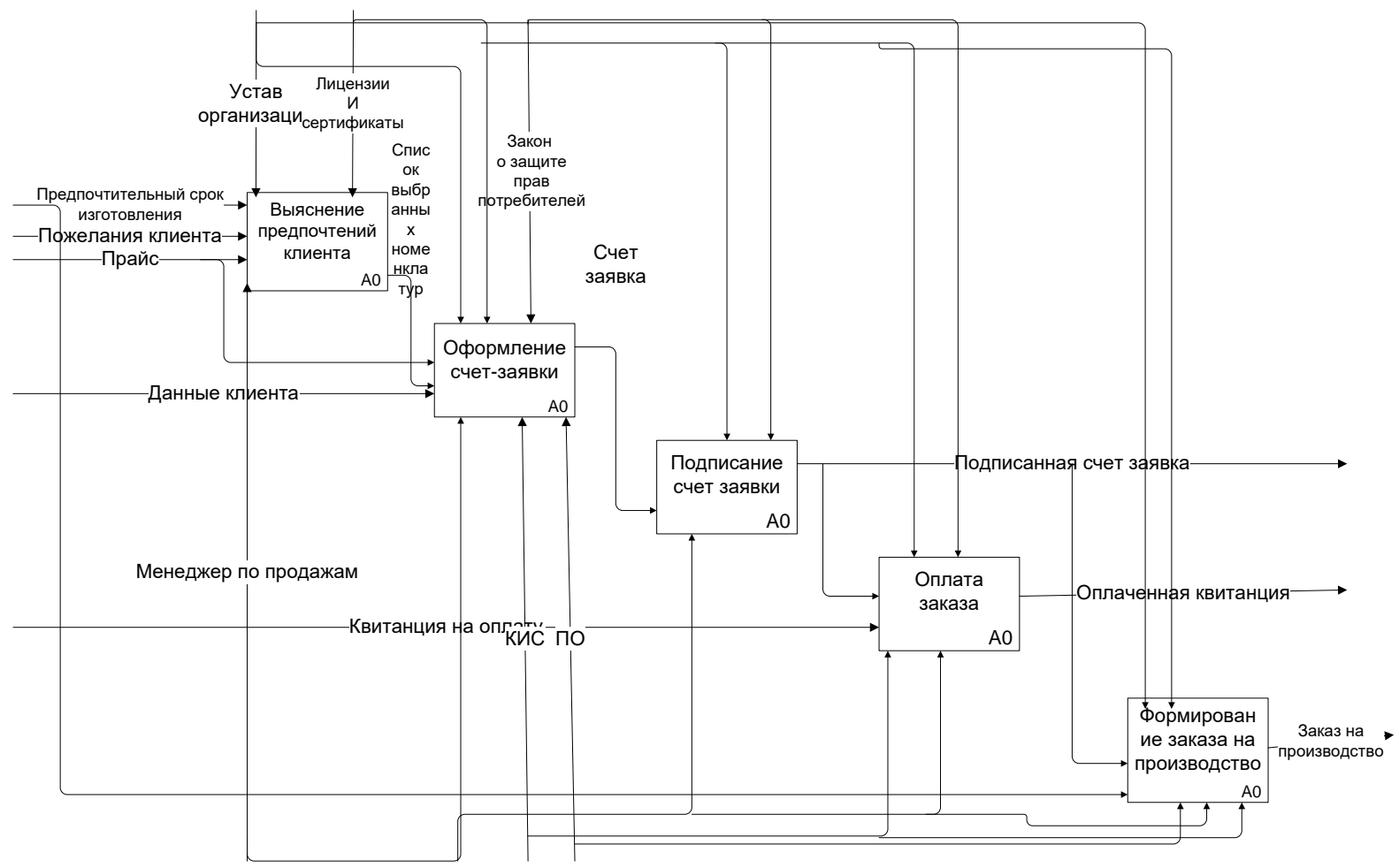

Рисунок 3 - Диаграмма декомпозициии функичональной IDEF0-модели

«Организащия деятельности отдела сбыта»

На основе построенной модели документооборота был проведен анализ по определению степени покрытия бизнес-процессов функциональностью системы. Результаты представлены в таблице 1. 
Таблицุа 1

Степень покрытия бизнес-прочессов функииональностью системы

\begin{tabular}{|c|c|c|c|}
\hline Бизнес-процесс & Автоматизирован полностью & $\begin{array}{c}\text { Автоматизирован } \\
\text { частично }\end{array}$ & Не автоматизирован \\
\hline 1.Оформление счет-заявки & & & \\
\hline 2.Подписание счет- заявки & & & \\
\hline 3.Оплата счет-заявки & & & \\
\hline $\begin{array}{c}\text { 4. Формирование заказа на } \\
\text { производство }\end{array}$ & & & \\
\hline
\end{tabular}

\section{Степень документированности КИС}

КИС 1С:УПП была внедрена по решению руководства организации, на производственном предприятии имеются только приказы о внедрении системы.

\section{Уровень обученности конечных пользователей}

При внедрении системы консалтинговой компанией было проведено обучение менеджеров основным функциям, реализованным в системе. Для этого были разработаны краткие инструкции. Дальнейшее обучение происходит самостоятельно по мере необходимости. Новых сотрудников обучают уже коллеги, достигшие достаточного уровня в работе с системой.

Таким образом, в ходе проведенного аудита КИС 1С: УПП - «Управление торговлей» были выявлены следующие недостатки (моменты падения производительности):

- существующий функционал позволяет оформлять заявки, квитанции на оплату, отправлять заявки в производство, автоматически расставить стоимость той или иной номенклатуры. Но цены ставятся только с учетом общего прайса, скидки (например, оптовым клиентам) необходимо выставлять вручную;

- шаблоны стандартных заявок на розничных клиентов не предусмотрены;

- недостаточный уровень обученности сотрудников работе с системой и недостаточный уровень документированности приводит к тому, что функционал системы не используется в полном объеме;

- дополнительные временные и трудовые затраты возникают при оказании консультационных услуг клиентам;

- отсутствие web-интерфейса и возможности расчета клиентом стоимости заявки онлайн.

На производственном предприятии клиенто-ориентированная стратегия. Реализацию данной стратегии уже на протяжении трех лет поддерживает КИС, которая позволяет автоматизировать большинство бизнес-процессов компании, связанных с управлением продажами, управлением отгрузками, управлением платежами.

Как показывают результаты проведенного аудита существует ряд недостатков, которые снижают эффективность использования данной КИС и деятельность предприятия.

Таким образом, по результатам проведенного аудита выявлены основные направления развития:

\section{Развитие программы лояльности клиентов.}

Повышение лояльности предполагается достигнуть при помощи внедрения программы БонПро и почтовых систем, смс-сервисов

Нами была выбрана программа БонПро.

Бонусная система БонПро предназначена для повышения лояльности клиентов торговых компаний. Программа представлена в виде конфигурации на платформе $1 \mathrm{C}:$ Предприятие 8 и позволяет автоматизировать процесс накопления, списания и учета бонусных баллов, а также предоставления скидок по различным условиям. 


\title{
Обучение персонала
}

Ценность информационных технологий - это понятие не абстрактное, оно зависит от наличия людей, умеющих из этих технологий извлекать пользу. Поэтому одним из наиболее важных моментов перехода к работе в условиях изменения или внедрения новых ИТ является обучение персонала.

Квалифицированные сотрудники не только смогут обеспечить стабильность и эффективность работы, но и многократно повысят стоимость самой компании.

$$
\text { *** }
$$

1. Назарова О.Б., Давлеткиреева Л.З. Интеграция автоматизированных информационных систем в сфере продаж холдинговой компании//Актуальные вопросы научной и научно-педагогической деятельности молодых учёных: сборник научных трудов всероссийской заочной научнопрактической конференции/под ред. Е.С. Ефремовой. Москва, 2015. - С. 86-96.

2. Назарова О.Б., Давлеткиреева Л.З., Малахова И.В.Аудит информа-ционной инфраструктуры компании и разработка ИТ-стратегии: монография/О.Б. Назарова, Л.З. Давлеткиреева, И.В. Малахова. -Магнитогорск: Магнитогорский гос. ун-т, 2012. -223 с.

3. Назарова О.Б., Новикова Т.Б., Петеляк В.Е. К вопросу разработки диа-граммы «архитектура системы -ASD»//B сборнике: Современная наука: теоретический и практический взгляд Сборник статей Международной научно-практической конференции. Ответственный редактор: Сукиасян Асатур Альбертович. 2015. С. 75-77.

4. Аудит ИТ-деятельности [Электронный ресурс]. - Режим доступа: http://www.itexpert.ru/rus/consulting/catalogue/inspaudit/audit/

\section{Юркова О.Н.}

Автоматизированная информационная система для оценки принадлежности иностранных студентов к группе риска хронических заболеваний

\author{
ФГБОУ ВО «БГИТУ» \\ (Россия, Брянск)
}

doi:10.18411/spc-12-11-2017-09

idsp: 000001:spc-12-11-2017-09

\section{Аннотация}

Разработана информационная система, в которой автоматизирован процесс прохождения скрининг-теста AUDIT иностранными студентами, одобренного ВO3.

Ключевые слова: автоматизированная информационная система; хронические заболевания; иностранные студенты, скрининг-тест.

Усиление процессов международного сотрудничества, мобильности учащейся молодежи, повышения престижности российского образования приводит к увеличению числа иностранных граждан среди учащихся российских вузов. В то же время уровень здоровья иностранных студентов вызывает особые опасения, потому что не только отсутствуют сведения об исходном состоянии их здоровья, но и существует повышенная вероятность его резкого ухудшения, т. к. стрессорное влияние учебной деятельности и других социальных факторов усугубляется напряжением адаптационных механизмов, связанных со сменой климатических условий проживания. Тем более что климатические условия Брянского региона являются экстремальными для уроженцев Африки, Средней Азии и многих других регионов, резко отличающихся по комплексу ландшафтно-климатических характеристик (уровню инсоляции, температурному режиму, влажности воздуха и т. д.). Поэтому существует повышенный риск возникновения различных заболеваний, в т. ч. хронических и инфекционных. Вместе с тем экспресс-тестирование состояния здоровья иностранных студентов вызывает особые затруднения, связанные с языковыми, организационными и другими проблемами.

На сегодняшний день в России не существует автоматизированной комплексной оценки состояния здоровья иностранных граждан. Существует лишь возможность оценки единичных показателей, например, оценки психоэмоционального состояния, которые используются как для российских, так и иностранных студентов, поскольку в 